\title{
An Adult Case of Multiple Squamous Papillomas of the Trachea Associated with Human Papilloma Virus Type 6
}

\author{
Hideki Shibuya ${ }^{1}$, Tomoko Kutomi ${ }^{2}$, Kosei Kujime ${ }^{1}$, Kei Hara ${ }^{1}$ and Tetsuya Hisada ${ }^{1}$
}

\begin{abstract}
A 72-year-old woman with primary biliary cirrhosis complained of dry cough and wheezing. Chest computed tomography showed a tumor arising from the posterior wall of the trachea. Bronchoscopic examination revealed that the tumor was cauliflower-like, with two small polypoid tumors. They were diagnosed as multiple squamous papillomas. The main tumor was recurrent and removed by repeated microwave coagulation therapy (MCT) through bronchoscopy, whereas the two polypoid tumors were likely to disappear spontaneously. Human papilloma virus (HPV) type 6 DNA was detected in the tumor by polymerase chain reaction (PCR) amplification, suggesting that this virus was the cause of her papillomas.
\end{abstract}

Key words: multiple papilloma, human papilloma virus, recurrent, microwave coagulation therapy, polymerase chain reaction

(Inter Med 47: 1535-1538, 2008)

(DOI: 10.2169/internalmedicine.47.1239)

\section{Introduction}

Multiple papillomas occur most commonly in the larynx and lower respiratory tract of children, although they have also been described in adults (1). They are manifestations of human papilloma virus (HPV) infection (2). Here, we report an elderly woman case of multiple squamous papillomas of the trachea. The main tumor was recurrent and removed by repeated microwave coagulation therapy (MCT) through bronchoscopy, whereas the two small polypoid tumors were thought to disappear spontaneously. The presence of HPV type 6 DNA in her papilloma biopsy sample was confirmed by polymerase chain reaction (PCR) amplification, suggesting that this virus was the cause of her papillomas.

\section{Case Report}

A 72-year-old woman, who had been admitted to the department of gastroenterology of our hospital for the treatment of esophageal varices due to primary biliary cirrhosis, complained of dry cough and wheezing in February 2005. Her symptoms gradually worsened, and she was referred to our department two months later. She had no history of smoking. Pulmonary examination showed that expiratory wheezing was audible on auscultation, and her physical examination was otherwise normal except that slight pitting edema was observed on both crura. Her laboratory data showed thrombocytopenia $\left(9.3 \times 10^{4} / \mu \mathrm{L}\right)$, hypoalbuminemia (3.1 g/dL), decreased level of choline esterase (134 IU/L), slight elevation of aminotransferase (aspartate aminotransferase $45 \mathrm{IU} / \mathrm{L}$, alanine aminotransferase $47 \mathrm{IU} / \mathrm{L}$ ), and slight hyperbilirubinemia $(1.2 \mathrm{mg} / \mathrm{dL})$, reflecting the presence of liver cirrhosis. Pulmonary function tests revealed a severe obstructive impairment: a forced vital capacity (FVC) of $2.40 \mathrm{~L}$ (108.1\% of predicted), a forced expiratory volume in $1 \mathrm{~s}\left(\mathrm{FEV}_{1.0}\right)$ of $0.62 \mathrm{~L}$ (38.7\% of predicted), a $\mathrm{FEV}_{1.0}$ to FVC ratio of $25.8 \%$, and a peak expiratory flow of $1.01 \mathrm{~L} / \mathrm{s}$ (18.9\% of predicted). Results of chest radiograph were unremarkable. Chest computed tomography revealed a tumor, 8 $\mathrm{mm}$ in size, arising from the posterior wall of the trachea (Fig. 1). On bronchoscopic examination, the tumor was located at the fourth tracheal ring from the carina, and had a cauliflower-like shape with mucus on its surface (Fig. 2A). In addition, two small polypoid lesions were observed at one ring above the main tumor (Fig. 2A). No tumorous le-

${ }^{1}$ Department of Respiratory Medicine, Tokyo Teishin Hospital, Tokyo and ${ }^{2}$ Department of Respiratory Medicine, University of Tokyo Graduate School of Medicine, Tokyo

Received for publication April 22, 2008; Accepted for publication May 23, 2008

Correspondence to Dr. Hideki Shibuya, ccz86020@hkg.odn.ne.jp 
sions were seen in the larynx or the bronchi. Biopsy was performed for the main tumor and one of the polypoid tumors. Microscopic findings of both the main tumor and the polypoid lesion showed squamous papilloma with mild atypia (Fig. 3), thus she was diagnosed with multiple squamous papillomas of the trachea.

She was referred to Tokyo Medical University Hospital in June 2005, and underwent bronchoscopy. Most of the main tumor was removed by biopsy and brushing, because of its fragility. MCT was performed for the remaining tumor through bronchoscopy (Fig. 2B). Interestingly, both of the two small polypoid tumors, which had been observed at our hospital only one month earlier, had disappeared by this time.

After treatment, she had been followed up regularly at our hospital with no respiratory symptoms, but bronchoscopic test showed the recurrence of the main tumor in March 2006 (Fig. 2C). No other lesions were observed. Biopsy was performed once again and the same pathological result was obtained. The biopsy sample was sent to a laboratory (SRL Company, Tokyo, Japan) and analyzed for the presence of HPV types $6,11,16,18,31,33,42,52$, or 58 by PCR. HPV DNA was amplified and the subsequent restriction mapping pattern showed the presence of HPV type 6 DNA

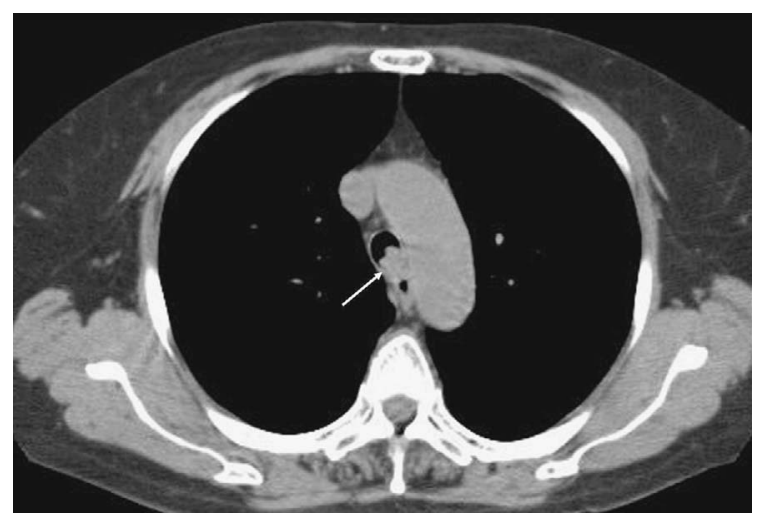

Figure 1. Chest computed tomography scan (April 2005) showing a tumor, $8 \mathrm{~mm}$ in size, arising from the posterior wall of the trachea (arrow). in the tumor (Fig. 4) (3), suggesting that her papillomas were caused by HPV type 6. She was referred to Tokyo Medical University Hospital once again and underwent MCT for the recurrent tumor.

\section{Discussion}

Tracheobronchial papillomas have three distinct clinical presentations: multiple papillomas, inflammatory polyps, or solitary papillomas (4). Multiple papillomas originate primarily in the larynx, with a tracheal incidence of about $2 \%$ (5) and lung involvement of $<1 \%$ (6). They have been divided into juvenile and adult types, because they present distinct clinical courses and different incidence of malignant transformation, according to the age at onset and the presence or absence of laryngeal involvement (7). Thus only a few adult cases of laryngeal papillomas spread into the inferior airways, and in most adult cases, multiple papillomas of tracheobronchial system occur without laryngeal involvement (8), as was observed in the present case. Moreover, it should be noted that almost all of the adult cases of laryn-

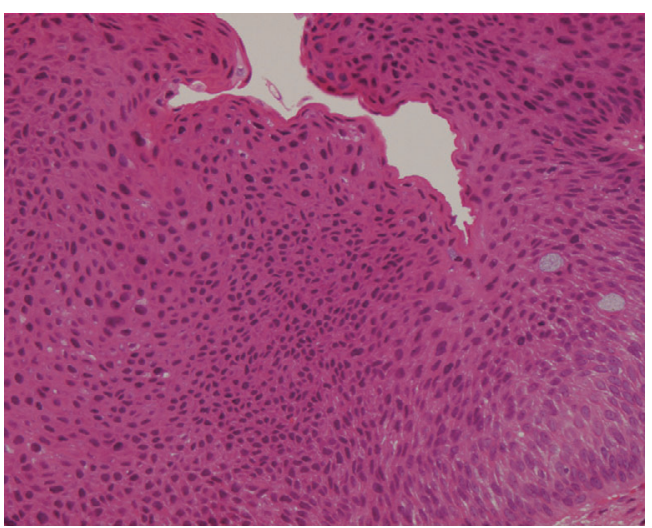

Figure 3. Microscopic findings of the main tumor revealing a papillary structure, covered by stratified squamous epithelium with mild atypia (Hematoxylin and Eosin staining, original magnification $\times 200$ ). Similar findings were obtained for one of the polypoid tumors.
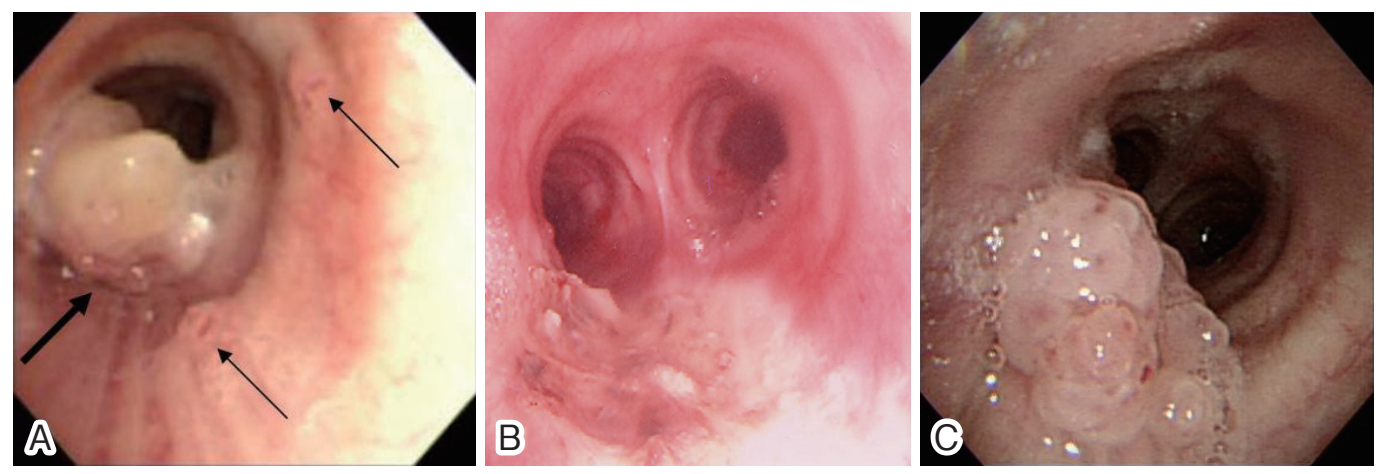

Figure 2. A: Bronchoscopic view of the trachea showing a cauliflower-like tumor with mucus on its surface (thick arrow) and two small polypoid tumors (thin arrows)(May 2005). B: After MCT (June 2005). Note that both of the two polypoid tumors had disappeared by this time (compare with Fig. 2A). C: Bronchoscopic test showing the recurrence of the main tumor (March 2006). 


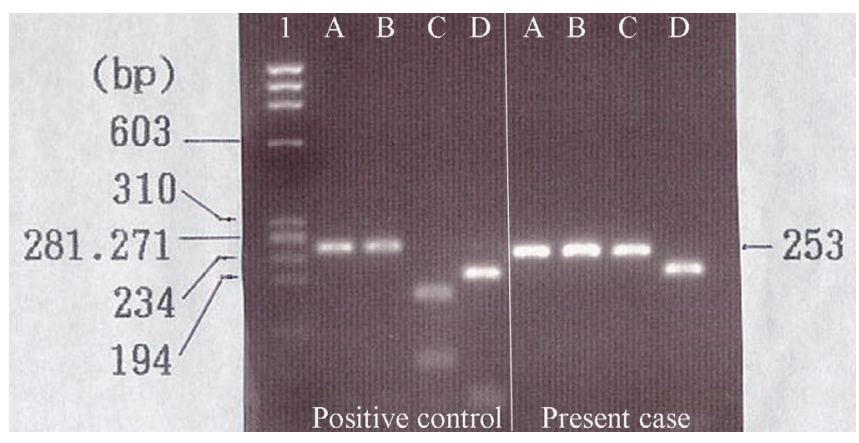

Figure 4. Restriction mapping of the amplified HPV DNA from the tumor biopsy sample. The PCR product was cut with the following restriction enzymes, A, uncut; B, Rsa I; C, Dde I; D, Hae III. This mapping pattern showed the presence of HPV type 6 DNA (3). Lane 1, size markers. Positive control, SiHa cells infected by HPV type 16.

geal papillomas which spread into the inferior airways or tracheobronchial papillomas without laryngeal involvement have been men with a high incidence of malignant transformation (8-10).

Multiple papillomas are associated with HPV infection (2) and it was reported that low-risk (i.e., low malignant potential) HPV types 6 and 11 cause about $90 \%$ of cases of recurrent respiratory papillomatosis (11). A previous study (2) showed a predominance of HPV type 11 or double infections that included HPV type 6 and type 11, consistent with the results of others (12). Thus, infection with HPV type 6 alone was identified in only $20 \%$ of the papillomas and $5.3 \%$ of the non-diseased sites by PCR (2). It is unclear why HPV type 11 is more likely to be identified, since HPV types 6 and 11 have greater than 50\% homology and thus are similar in genetic makeup. In the present case, only HPV type 6 was detected in the tumor, which is considered to be relatively rare.

Of note, in the present case, the polypoid tumors were likely to disappear spontaneously, whereas the main tumor was recurrent. Indeed, spontaneous regression has been reported in juvenile types of papillomatosis (13). In this context, the importance of an effective immune system in the resolution of HPV infection has been described (14). Although the precise mechanisms of spontaneous regression in the present case are not known, it is quite possible that improved local immune responses at sites of the polypoid tumors might eliminate latent HPV infection or prevent its activation, resulting in spontaneous regression.

Laser technique and other developed coagulation methods (e.g., MCT performed in the present case) make it possible to remove most papillomas through bronchoscopy, with only little risk to the patient (15). Photodynamic therapy, originally developed for the diagnosis and treatment of cancer, has been applied to the treatment of papillomatosis, with promising results (16). Papillomas that show signs of atypia and peribronchial spreading or that cannot be reached by bronchoscopy sometimes require chest surgery (15). The papillomas in the present case showed mild atypia, but MCT was performed for the following reasons. First, the main tumor was so fragile that most of it could be removed by biopsy and brushing. Second, it was possible that both of the two polypoid tumors would disappear spontaneously. Third, because of her underlying liver disease with esophageal varices, surgical operation may have been too high a risk for her. The recurrence was localized to the main tumor and it could be removed by MCT once again.

It is generally accepted that low-risk HPV type 6 or 11 positivity is associated with a benign clinical course in most cases, whereas high-risk oncogenic HPV-16 or 18 is always accompanied by a poor prognosis (17). However, some reports have demonstrated that squamous cell carcinoma arose from papilloma lesions in which HPV type 6 or 11 was positive $(18,19)$. These results suggest that HPV types 6 and 11 under certain circumstances might have a carcinogeneic or cocarcinogeneic effect in the respiratory tract (19). Factors such as cigarette smoking, irradiation, cytotoxic drugs, and perhaps other DNA-damaging viruses must be involved in the malignant transforming process (19). There are also spontaneous genetic changes which cause malignant transformation, such as p53 mutation (20). Indeed, it was reported that p53 genetic mutation was associated with integration of HPV type 11 in histologically malignant lesions in recurrent respiratory papillomatosis (20).

The present case is rare for the following reasons. First, this is an elderly woman case of multiple papillomas localized to the trachea without laryngeal involvement; such findings have been reported predominantly in adult man cases (8-10). Second, only HPV type 6 was detected in the tumor. Third, it is likely that both of the two polypoid tumors regressed spontaneously, whereas the main tumor was recurrent. Careful follow-up studies are required for the early detection of local recurrence, malignant transformation, and recurrence at other sites.

\section{Acknowledgement}

We wish to thank Drs. Hidemitsu Tsutsui and Harubumi Kato of Tokyo Medical University Hospital for performing MCT.

\section{References}

1. Glazer G, Webb WR. Laryngeal papillomatosis with pulmonary spread in a 69-year-old man. Am J Roentgenol 132: 820-823, 1979.

2. Smith EM, Pignatari SSN, Gray SD, Haugen TH, Turek LP. Human papillomavirus infection in papillomas and nondiseased respi- ratory sites of patients with recurrent respiratory papillomatosis using the polymerase chain reaction. Arch Otolaryngol Head Neck Surg 119: 554-557, 1993.

3. Yoshikawa H, Kawana T, Kitagawa K, Mizuno M, Yoshikura H, Iwamoto A. Detection and typing of multiple genital human papil- 
lomaviruses by DNA amplification with consensus primers. Jpn J Cancer Res 82: 524-531, 1991.

4. Drennan JM, Douglas AC. Solitary papilloma of a bronchus. J Clin Pathol 18: 401-402, 1965.

5. Singer DB, Greenberg SD, Harrison GM. Papillomatosis of the lung. Am Rev Respir Dis 94: 777-783, 1966.

6. Kramer SS, Wehunt WD, Stocker JT, Kashima H. Pulmonary manifestations of juvenile laryngotracheal papillomatosis. Am J Roentgenol 144: 687-694, 1985.

7. Lee E, Katakami N, Sakamoto H, et al. A case of papillomatosis of larynx and trachea. Kikanshi 8: 97-102, 1986 (in Japanese, Abstract in English).

8. Al-Saleem T, Peale AR, Norris CM. Multiple papillomatosis of the lower respiratory tract. Clinical and pathologic study of eleven cases. Cancer 22: 1173-1184, 1968.

9. Ogilvie OE. Multiple papillomas of trachea with malignant degeneration; report of two cases. AMA Arch Otolaryngol 58: 10-18, 1953.

10. DiMarco AF, Montenegro H, Payne CB Jr, Kwon KH. Papillomas of the tracheobronchial tree with malignant degeneration. Chest 74: 464-465, 1978.

11. Steinbrook R. The potential of human papillomavirus vaccines. $\mathrm{N}$ Engl J Med 354: 1109-1112, 2006.

12. Steinberg BM. Human papillomaviruses and upper airway oncogenesis. Am J Otolaryngol 11: 370-374, 1990.

13. Majoros M, Parkhill EM, Devine KD. Papilloma of the larynx in children. A clinicopathologic study. Am J Surg 108: 470-475,
1964.

14. Bonnez W, Reichman RC. Papillomaviruses. In: Mandell, Douglas, and Bennett's Principles and Practice of Infectious Diseases. 6th ed. Mandell GL, Bennett JE, Dolin R, Eds. Elsevier Inc., Philadelphia, 2005: 1841-1856.

15. Barzo P, Molnar L, Minik K. Bronchial papillomas of various origins. Chest 92: 132-136, 1987.

16. Kavuru MS, Mehta AC, Eliachar I. Effect of photodynamic therapy and external beam radiation therapy on juvenile laryngotracheobronchial papillomatosis. Am Rev Respir Dis 141: 509-510, 1990.

17. Popper HH, el-Shabrawi Y, Wockel W, et al. Prognositic importance of human papilloma virus typing in squamous cell papilloma of the bronchus: Comparison of in situ hybridization and the polymerase chain reaction. Hum Pathol 25: 1191-1197, 1994.

18. Zarod AP, Rutherford JD, Corbitt G. Malignant progression of laryngeal papilloma associated with human papilloma virus type 6 (HPV-6) DNA. J Clin Pathol 41: 280-283, 1988.

19. Guillou L, Sahli R, Chaubert P, Monnier P, Cuttat JF, Costa J. Squamous cell carcinoma of the lung in a nonsmoking, nonirradiated patient with juvenile laryngotracheal papillomatosis. Evidence of human papillomavirus-11 DNA in both carcinoma and papillomas. Am J Surg Pathol 15: 891-898, 1991.

20. Rady PL, Schnadig VJ, Weiss RL, Hughes TK, Tyring SK. Malignant transformation of recurrent respiratory papillomatosis associated with integrated human papillomavirus type 11 DNA and mutation of p53. Laryngoscope 108: 735-740, 1998.

(C) 2008 The Japanese Society of Internal Medicine http://www.naika.or.jp/imindex.html 